\title{
Insect herbivory on native and exotic aquatic plants: phosphorus and nitrogen drive insect growth and nutrient release
}

\author{
Bart M. C. Grutters • Elisabeth M. Gross • \\ Elisabeth S. Bakker
}

Received: 15 April 2015/Revised: 16 July 2015/Accepted: 13 August 2015/Published online: 27 October 2015

(C) The Author(s) 2015. This article is published with open access at Springerlink.com

\begin{abstract}
Eutrophication and globalisation facilitate the dominance of exotic plants in aquatic ecosystems worldwide. Aquatic omnivores can provide biotic resistance to plant invasions, but little is known about whether obligate aquatic herbivores can do the same. Herbivores such as insects can decimate aquatic vegetation, but may not be able to consume exotic plants due to their more or less specialised nature of feeding. We experimentally tested the larval feeding of an aquatic insect, the moth Parapoynx stratiotata, on eleven submerged plant species, from either native or exotic origin. We also tested whether insect herbivory stimulates nutrient and organic matter release, thus affecting water quality. Larvae of $P$.
\end{abstract}

Guest editors: M. Beklioğlu, M. Meerhoff, T. A. Davidson, K. A. Ger, K. E. Havens \& B. Moss / Shallow Lakes in a Fast Changing World

Electronic supplementary material The online version of this article (doi:10.1007/s10750-015-2448-1) contains supplementary material, which is available to authorized users.

B. M. C. Grutters $(\varangle)$ · E. S. Bakker

Department of Aquatic Ecology, Netherlands Institute of Ecology (NIOO-KNAW), Droevendaalsesteeg 10, 6708 PB Wageningen, The Netherlands

e-mail: b.grutters@nioo.knaw.nl

\section{E. M. Gross}

Laboratoire Interdisciplinaire des Environnements Continentaux (LIEC), UMR 7360, Université de Lorraine, Campus Bridoux, 57070 Metz, France stratiotata consumed seven out of eleven plant species, and their growth was related to plant nutrient content and stoichiometry. However, larvae had no preference for either native or exotic macrophytes, and their plant preference was not related to the measured plant traits, but was possibly driven by secondary metabolites. Through plant consumption, caterpillars induced brownification and phosphate release, and the intensity thereof varied among plant species, but not between native and exotic plants. In conclusion, $P$. stratiotata showed strong feeding preferences demonstrating that aquatic insects can directly and indirectly alter water quality and vegetation composition.

Keywords Aquatic caterpillar - Crambidae . Ecological stoichiometry $\cdot$ Invasive plants . Parapoynx stratiotata $\cdot$ Water brownification

\section{Introduction}

Eutrophication and globalisation cause a worldwide increase of invading exotic plants in aquatic ecosystems (Meyerson \& Mooney, 2007). Exotic plants are introduced through aquaculture and global plant trade (Kay \& Hoyle, 2001; Martin \& Coetzee, 2011; Hussner, 2012) and they rank among the top four threats to freshwater biodiversity (Dudgeon et al., 2006) with more than 96 invasive exotic aquatic plants already established in Europe (Hussner, 2012). They grow fast, disperse quickly and easily establish in 
eutrophied ecosystems (Simberloff et al., 2011). As a result, plant invaders dominate many disturbed habitats (MacDougall \& Turkington, 2005; Simberloff et al., 2011). Notorious aquatic plant genera are Hydrilla (L.f.) Royle, Myriophyllum L. and Elodea Michx., and their management costs millions of euros annually (Langeland, 1996; Oreska \& Aldridge, 2011; Zehnsdorf et al., 2015). An open question is whether native herbivores can provide biotic resistance to plant invasions. This will depend strongly on herbivore feeding preferences for certain plant species. There is contrasting evidence: native herbivores preferred exotic aquatic plant species in several studies (Parker \& Hay, 2005; Morrison \& Hay, 2011), but preferred native plants in other studies (Xiong et al., 2008). We hypothesised that the preference of native herbivores for certain plant species is related to the plant quality.

Plant nutrient content may affect both the invasiveness of plants and their susceptibility to herbivores. The growth rate hypothesis predicts that fast growth, often found in invasive plant species, requires rapid protein synthesis in plants, and much phosphorus-rich RNA (Sterner \& Elser, 2002). As both plant and herbivore growths are limited mostly by nitrogen (N) and phosphorus (P) (Mattson, 1980; Barko \& Smart, 1986; Barko et al., 1988; Smith et al., 1999), rapidly growing plants may be better food for herbivores than slow growing ones, because the $\mathrm{N}$ and $\mathrm{P}$ contents of such plants are relatively high. For example, rudd and grass carp prefer aquatic plants with lower $\mathrm{C}: \mathrm{N}$ ratios, resulting from a higher $\mathrm{N}$ content (Dorenbosch \& Bakker, 2011). Besides elemental stoichiometry, plants can differ in chemical feeding deterrents, and also in the ratio of deterrents to feeding attractants (Cronin et al., 2002; Gross \& Bakker 2012). The aquatic caterpillar Acentria ephemerella Denis \& Schiffermüller can grow on the chemically well-defended $M$. spicatum, but it grows better on the more nutritious, less-defended $P$. perfoliatus L. (Choi et al., 2002). Similarly, fish ate more of the well-defended $M$. spicatum when it contained more nitrogen (Dorenbosch \& Bakker, 2011). Interestingly, foliar traits differ between native and exotic species (Penuelas et al., 2010). Therefore, native herbivores could potentially restrict exotic plant growth and allow growth of other plant species by selective consumption, if exotic plants are favoured food items.
Until now, herbivore preferences for exotic or native aquatic plant species have been mainly studied using omnivorous animals. However, specialist herbivores may suppress exotic plant growth better than omnivores, even though aquatic habitats contain fewer specialist herbivores than terrestrial habitats (Newman, 1991; Harrison et al., 2008; Gross \& Bakker, 2012). More specialised herbivores can be effective agents of biotic resistance, such as milfoil weevils (Euhrychiopsis lecontei Dietz) and the aquatic moth Acentria ephemerella that consume exotic M. spicatum (Johnson et al., 1997, 2000; Solarz \& Newman, 2001). In addition, plants cannot easily recover from insect herbivory through regrowth, because many insects target not only leaves, but also stems and apical meristems (Newman, 1991; Johnson et al., 1997, 2000; Choi et al., 2002; Fornoff \& Gross, 2014). The massive outbreak of insect herbivores can decimate dense stands of macrophytes and alter the plant species composition by direct feeding impacts (Johnson et al., 1997, 2000; Gross et al., 2001). Furthermore, they can indirectly affect vegetation composition by releasing nutrients and organic compounds through excretion following the consumption of large amounts of macrophytes (Newman, 1991; Vanni, 2002). The microbial degradation of dissolved organic compounds into humic acids can then cause brownification of the water (Roulet \& Moore, 2006; Graneli, 2012), which affects light availability and vegetation composition (Mormul et al., 2012).

In this study, we assessed the preference of a herbivorous insect for native and exotic plant species, and we investigated how its consumption affects nutrient release and water quality. We expected that plant stoichiometry and nutrient content, but not plant origin, would explain herbivore preference and herbivore-induced effects on water quality.

\section{Materials and methods}

\section{Study species}

The Ringed China-mark (Parapoynx stratiotata L. 1758; Crambidae) is a native European moth with an aquatic larval stage that requires host plants for habitat and food (Lekic, 1971; Vallenduuk \& Cuppen, 2004). Field observations showed that $P$. stratiotata can decimate aquatic vegetation (Gaevskaya, 1969; 
Spencer \& Lekic, 1974), but apart from anecdotal evidence, little is known about the moth's feeding patterns, its growth and its effects on nutrient release. We tested whether or not the palatability of native and exotic macrophytes to $P$. stratiotata differs. Eleven macrophyte species were collected from experimental ponds located at the Netherlands Institute of Ecology (51.988' N, 5.672' E) in July 2013. These aquatic plants are now all common in Northwestern Europe and frequently form dense vegetation in eutrophic freshwaters. We tested six native vascular plants: Myriophyllum spicatum L., M. verticillatum L., Ranunculus circinatus Sibth, Potamogeton lucens L., P. pusillus L. and Ceratophyllum demersum $\mathrm{L}$. and one native charophyte: Chara contraria A Braun ex Kützing. In addition, four exotic vascular plants were fed to caterpillars: $M$. aquaticum (Vell.) Verdc. (native range: South America), $M$. heterophyllum Michx (native range: North America), Cabomba caroliniana A. Gray (native range: North and South America) and Elodea nuttallii (Planch.) H. St. John (native range: North America).

Feeding trials

We used no-choice feeding trials to determine the palatability of the plant species to the caterpillars, following the design of feeding trials for pond snails (Elger \& Lemoine, 2005). We rinsed freshly collected plant parts under running tap water and prepared portions of non-apical shoots ( $0.5 \mathrm{~g}$ fresh mass), or in the case of $P$. lucens: whole leaves. We carefully blotted plant parts dry with paper towel and weighed them to the nearest milligram fresh mass before use in the feeding trials.

We collected caterpillars from plant culturing tanks at the Netherlands Institute of Ecology for use in the experiment. Larvae were held in tap water $\left(19^{\circ} \mathrm{C}\right)$ for $24 \mathrm{~h}$ prior to feeding trials. We used three larvae in each experimental unit to reduce variation in feeding. Larvae were divided into three groups based on their body length (small: 10-12 mm, medium: 13-15 mm and large: $16 \mathrm{~mm}$ or greater), and we randomly added one individual from each size group to experimental units with herbivores. For the feeding trials, we used eight experimental units per plant species: four with added herbivores and four without herbivores to account for autogenic changes in plant mass (Elger \& Barrat-Segretain, 2002). Rectangular plastic trays $(11 \times 15.5 \times 5 \mathrm{~cm})$ filled with $500 \mathrm{ml}$ tap water served as experimental units. At the start of the experiment, we added plant portions to all trays, photographed them and then released caterpillars in half of the trays per plant species. Plant biomass was abundant to allow unrestricted feeding during the experiment. We placed all trays in a room $\left(19^{\circ} \mathrm{C}\right)$ with daylight and allowed larvae to feed for $96 \mathrm{~h}$. Larvae were then transferred to trays with fresh tap water where we waited for them to empty their gut (i.e. it was not visibly green, brown or black) prior to freezing them in Eppendorf tubes. Later we unfroze larvae, dried them at $60^{\circ} \mathrm{C}$ and weighed them (mg dry mass). We measured the carbon and nitrogen content of caterpillars using a FLASH 2000 organic elemental analyser (Interscience BV, Breda, the Netherlands) and measured the phosphorus content by incinerating samples at $550^{\circ} \mathrm{C}$ for $30 \mathrm{~min}$, autoclaving them in a $2 \%$ potassium persulfate $\left(\mathrm{K}_{2} \mathrm{~S}_{2} \mathrm{O}_{8}\right)$ solution at $121^{\circ} \mathrm{C}$ before measuring phosphate levels of the supernatant using a QuAAtro segmented flow AutoAnalyzer (Beun de Ronde, Abcoude, the Netherlands). At the end of the trial, leftover plant fragments were removed from the trays, blotted dry and weighed to the nearest milligram fresh mass. Subsequently, we dried the fragments $\left(60^{\circ} \mathrm{C}\right.$ to constant dry mass) and weighed them once more to determine post-experiment dry mass. Also we analysed the water of each experimental unit, and of four tap water background samples, for nitrate, nitrite, ammonium and orthophosphate using an AutoAnalyzer (QuAAtro, Seal Analytical, Fareham, UK). We quantified brownification of the water based on absorbance at $510 \mathrm{~nm}$ (Lambda 800, PerkinElmer, Waltham, USA) (Smolders et al., 2003).

\section{Chemical plant analyses}

We measured the nitrogen $(\mathrm{N})$, carbon $(\mathrm{C})$, phosphorus $(\mathrm{P})$, dry matter (DMC) and total phenolics content (TPC) of all plant fragments. Dry plant fragments were finely ground using a ball grinder (Retch MM301, Haan, Germany). We measured $\mathrm{C}$ and $\mathrm{N}$ contents of the ground dried plant material using an organic elemental analyser (FLASH 2000, Thermo Scientific, Waltham, MA, USA). We determined the P content of plant fragments by incinerating $500 \mu \mathrm{g}$ at $500^{\circ} \mathrm{C}$ for $30 \mathrm{~min}$, then digesting the remainder with $5 \mathrm{ml}$ of $2.5 \%$ persulfate in an autoclave $\left(30 \mathrm{~min}\right.$ at $\left.121^{\circ} \mathrm{C}\right)$ before analysing phosphorus of the supernatant on an AutoAnalyzer (QuAAtro method Q-037-05, Seal 
Analytical, Fareham, UK). To analyse plant TPC, we extracted plant material with $80 \%$ ethanol for $10 \mathrm{~min}$ at $80^{\circ} \mathrm{C}$, then we added sodium dodecyl sulphate solution and $\mathrm{FeCl}_{3}$ reagent and measured the absorbance at $510 \mathrm{~nm}$ on a spectrophotometer in triplicate (Synergy HT Microplate Reader, BioTek, Winooski, VT, USA) against a tannic acid calibration curve (Mole \& Waterman, 1987; Smolders et al., 2000).

\section{Data analysis}

We determined whether caterpillars had consumed plant species or not by analysing the difference between pre- and post-experiment plant fresh mass. We incremented each difference, referred to as fresh mass change, with $48 \mathrm{mg}$ to remove negative and zero values. These negative values were caused either by plant growth, or by variance in the extent of blotting plant fragments dry. We then assessed whether the square-root transformed fresh mass change differed between control versus herbivory treatments using a two-way ANOVA (factors: plant species x herbivory). The ANOVA justified whether or not we could perform post hoc tests of pair-wise contrasts between both treatments for each plant species. We compared the square-root transformed fresh mass change among the consumed plant species using the appropriate post hoc contrasts. In addition, we assessed whether or not mean caterpillar consumption differed between native and exotic plant species using a separate ANOVA (factors: plant origin and plant species).

Variations in feeding and in the pooled caterpillar dry mass were analysed using ANOVA and regression. The following plant parameters were included: C, N, P, C:N, C:P, N:P, DMC, and TPC. We assessed indirect effects of herbivory on water nutrients and brownification using ANOVA to compare herbivore to control treatments and to compare interspecific differences. We excluded one outlier for $C$. demersum phosphate measurements as it was much lower than all other values and caused problems with model assumptions, however if included, the results were similar and also significant. Subsequently, we performed separate ANCOVAs on water phosphate and brownification including plant species as a factor and the fresh mass eaten by caterpillars as a covariate.

We checked that the final statistical models fulfilled assumptions of homogeneity and normality. All data were analysed in $\mathrm{R}$ version 3.0.3 using the multcomp, MASS and car packages.

\section{Results}

Plant and herbivore stoichiometry

Plant stoichiometry, nutrient content and total phenolics content (TPC) varied strongly among plant species, but not between native and exotic plants (Table 1). On average, native and exotic plants had similar C:N, C:P, N:P, N, P and TPC values. The chemical composition of caterpillars differed at the end of the experiment, depending on the plant species they had been offered (Table 1). Furthermore, caterpillars had much lower $\mathrm{C}: \mathrm{N}$ and $\mathrm{C}: \mathrm{P}$ values than plants.

\section{Consumption}

The larvae of $P$. stratiotata consumed native $(0.25 \pm 0.09$, mean \pm SEM $)$ and exotic plants $(0.18 \pm 0.07$, mean $\pm \mathrm{SEM})$ in equal amounts (ANOVA; origin: $F_{1,33}=0.05, P=0.83$ ). However, we found large interspecific differences in consumption of the eleven tested aquatic plants (two-way ANOVA; herbivory treatment: $F_{1,66}=481$, $P<0.001$; plant species: $F_{10,66}=21, P<0.001$; interaction: $\left.F_{10,66}=22, P<0.001\right)$. Larvae consumed seven plant species and left four species unharmed: C. contraria, Myriophyllum verticillatum, $R$. circinatus and $C$. caroliniana (Fig. 1; within-plant post hoc: $P<0.05)$. For the plants eaten, $C$. demersum and Myriophyllum heterophyllum lost significantly more fresh mass to herbivory than E. nuttallii, $M$. spicatum and $P$. lucens (Fig. 1A; between plant post hoc: $P<0.05)$.

Feeding determinants and growth of $P$. stratiotata larvae

Larval plant consumption was not related to plant elemental stoichiometry, nutrient content, dry matter content or total phenolics content $(P>0.05$; Supplementary Material Fig. S1). However, the pooled final larval dry mass varied greatly between plant species (Fig. 1B; one-way ANOVA, $F_{10,33}=8.7, P<0.001$ ) 


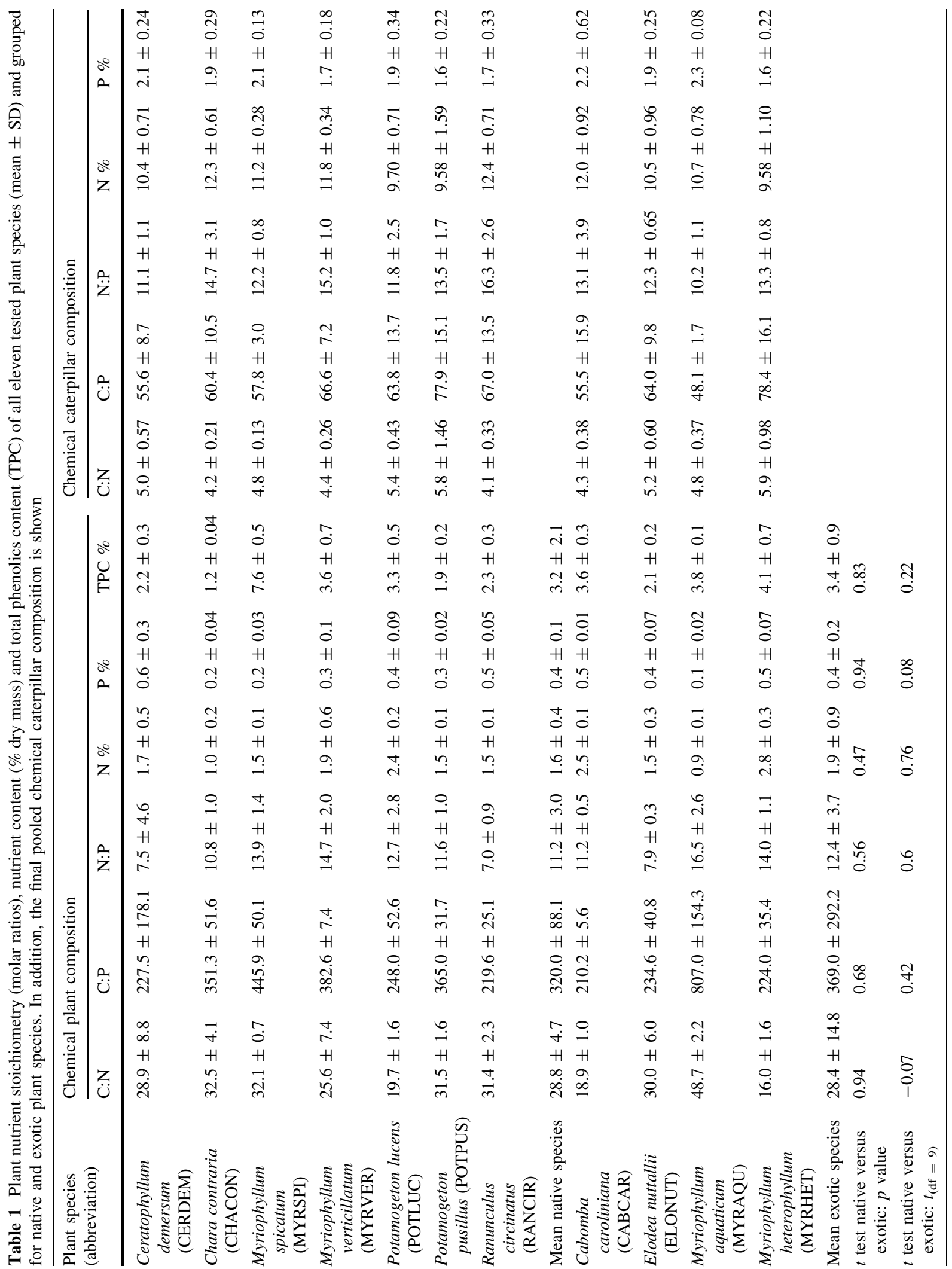




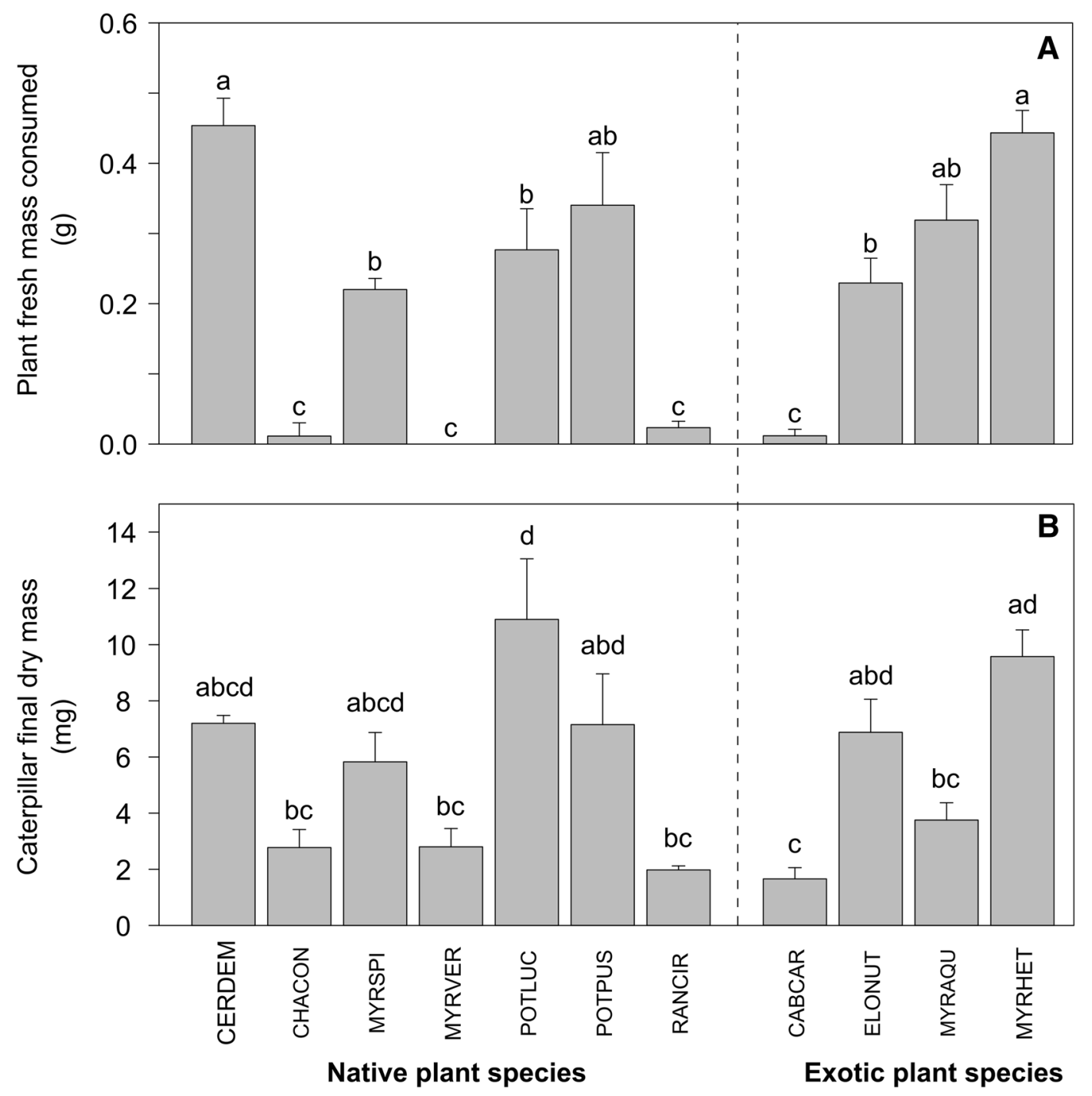

Fig. 1 Herbivore-induced fresh mass difference and the pooled caterpillar final dry mass for each of the eleven tested macrophyte species (mean $\pm \mathrm{SEM}, n=4$ ). Different letters

and was negatively related to the plant's C:N (Fig. 2; regression, $R^{2}=0.86 ; P=0.002$ ) and C:P ratio $\left(R^{2}=0.54 ; P<0.036\right)$, positively related to plant nitrogen content $\left(R^{2}=0.79 ; P=0.005\right)$, but not related to the plant phosphorus content $\left(R^{2}=0.28 ; P=0.13\right)$. Carbon content and TPC were not related to the final larval dry mass ( $P=0.76$ and $P=0.68$, respectively). Among plants, the plant phosphorus and nitrogen content were weakly positively correlated (Pearson correlation; $r=0.60, n=11, P=0.049)$. indicate statistically significant differences between plant species. Species abbreviations are listed in Table 1

Nutrient release

Herbivore presence resulted in higher water phosphorus concentrations (herbivory treatment: $F_{1,65}=$ 132.7, $P<0.001$ ) and water brownification (herbivory treatment: $F_{1,66}=110.7, P<0.001$; Supplementary Material Fig. S2), and the intensity of these herbivore-induced effects differed substantially among plant species (Fig. 3; for phosphate: $F_{10,31}=11.1$, $P<0.001$ and for brownification: $F_{10,66}=5.8, P<$ $0.001)$. The highest water phosphate concentration was 

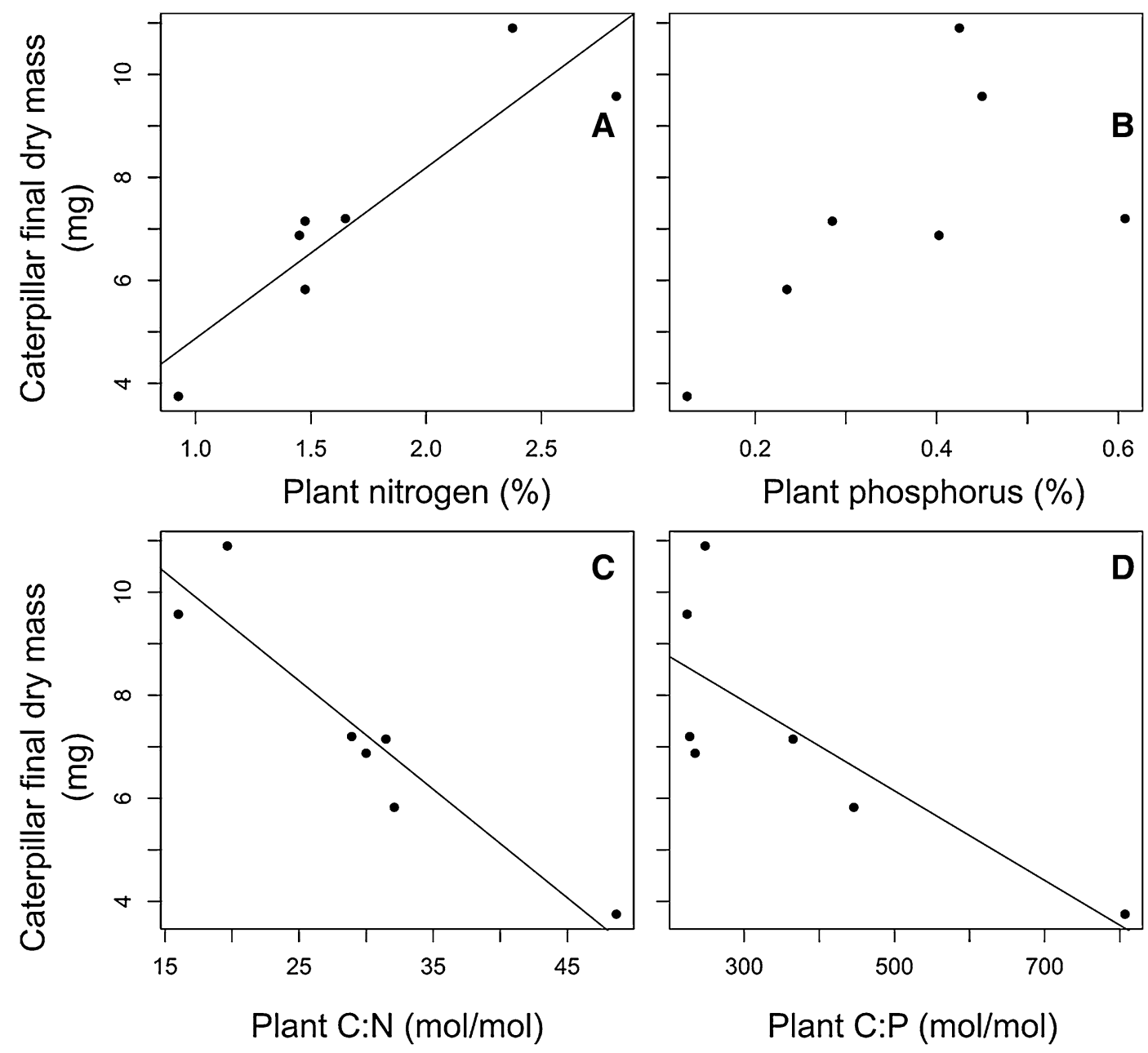

Fig. 2 Relationship between the pooled Parapoynx stratiotata final dry mass and the plant nitrogen content (A), phosphorus content (B), molar carbon-to-nitrogen ratio $(\mathbf{C})$ and molar carbon-to-phosphorus ratio (D)

found in the presence of herbivores in the C. demersum, E. nuttallii, M. heterophyllum, P. lucens and P. pusillus treatments (Fig. 3A). Brownification was most pronounced when herbivores fed on E. nuttallii, $M$. spicatum, P. lucens and P. pusillus, with absorbance values reaching 0.015-0.020 (Fig. 3B). Furthermore, the water phosphate concentration $\left(F_{1,31}=11.9, P=\right.$ $0.002)$, but not brownification $\left(F_{1,32}=1.5, P=0.23\right)$, depended on the amount of fresh mass consumed by caterpillars. Phosphate release was also positively related to the plant phosphorus content (Fig. 4; regression, $R^{2}=0.8, P=0.010$ ), but if the plant phosphorus content was tested with the fresh mass consumed using multiple regression, the latter was not significant $\left(F_{1,4}=0.8 ; P=0.43\right)$. In contrast to phosphate, herbivory did not increase levels of nitrate, nitrite, or ammonium in the water, as we found similar concentrations in herbivore treatments compared to the controls (within-plant post hoc analyses: $P>0.05)$.

\section{Discussion}

In our study, on average, native and exotic plants possessed similar stoichiometry, nutrients and total phenolics content, although the range for both groups was large due to the inclusion of species from different plant families. In accordance with this finding, aquatic larvae of $P$. stratiotata consumed 


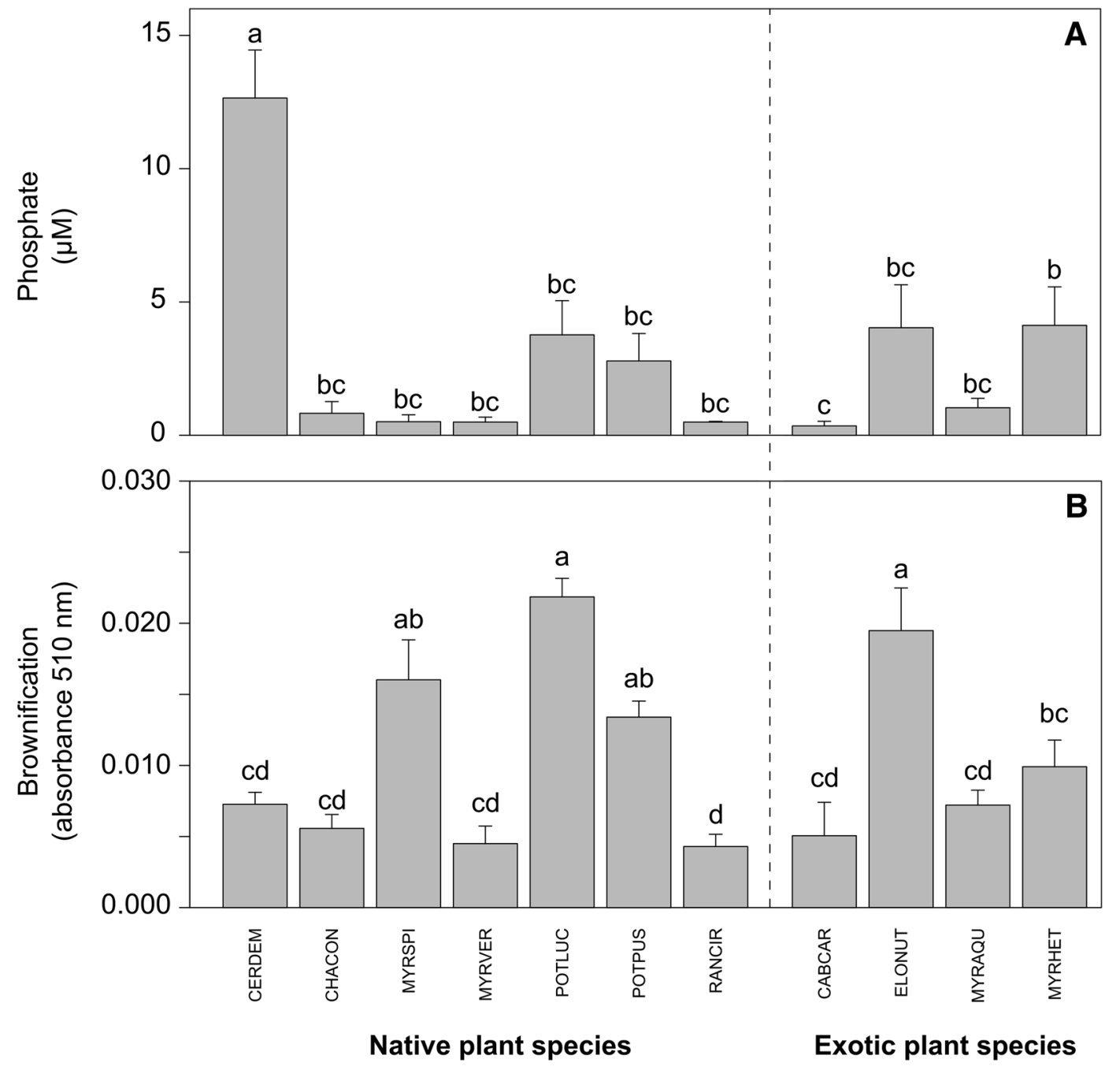

Fig. 3 Water phosphate concentration and water brownification for each of the eleven tested macrophyte species (mean $\pm \mathrm{SEM}, n=4$ except for $C$. demersum phosphate:

similar amounts of native and exotic plants. These results do not point to enemy release, which would have been the case if exotic plant species had not been consumed by native caterpillars of $P$. stratiotata (Keane \& Crawley, 2002; Colautti et al., 2004). Instead of enemy release, we found that $P$. stratiotata can provide biotic resistance to the invasion by a number of exotic plant species, as three of the four species that we tested were eaten by the caterpillars. The main challenge for $P$. stratiotata seems not coping with plant origin, but tackling the stoichiometric mismatch between the CNP ratios of itself relative to its food. $n=3$ ). Different letters indicate statistically significant differences between plant species. Species abbreviations are listed in Table 1

Most aquatic insect herbivores are polyphagous, especially lepidopterans (Newman, 1991), which $P$. stratiotata demonstrates by feeding on seven out of the eleven macrophytes that we offered. Unlike weevils, lepidopterans such as $P$. stratiotata are not restricted to a specific plant genus or family (Newman, 1991). Instead we expected the caterpillar to respond to plant traits. Unexpectedly, however, none of the stoichiometric, nutrient or defence traits explained the consumption patterns for $P$. stratiotata. Whereas plant stoichiometry influences consumption by omnivorous generalist crayfish, fish, snails, ducks and amphipods (Bolser et al., 1998; Cronin et al., 2002; Elger \& 


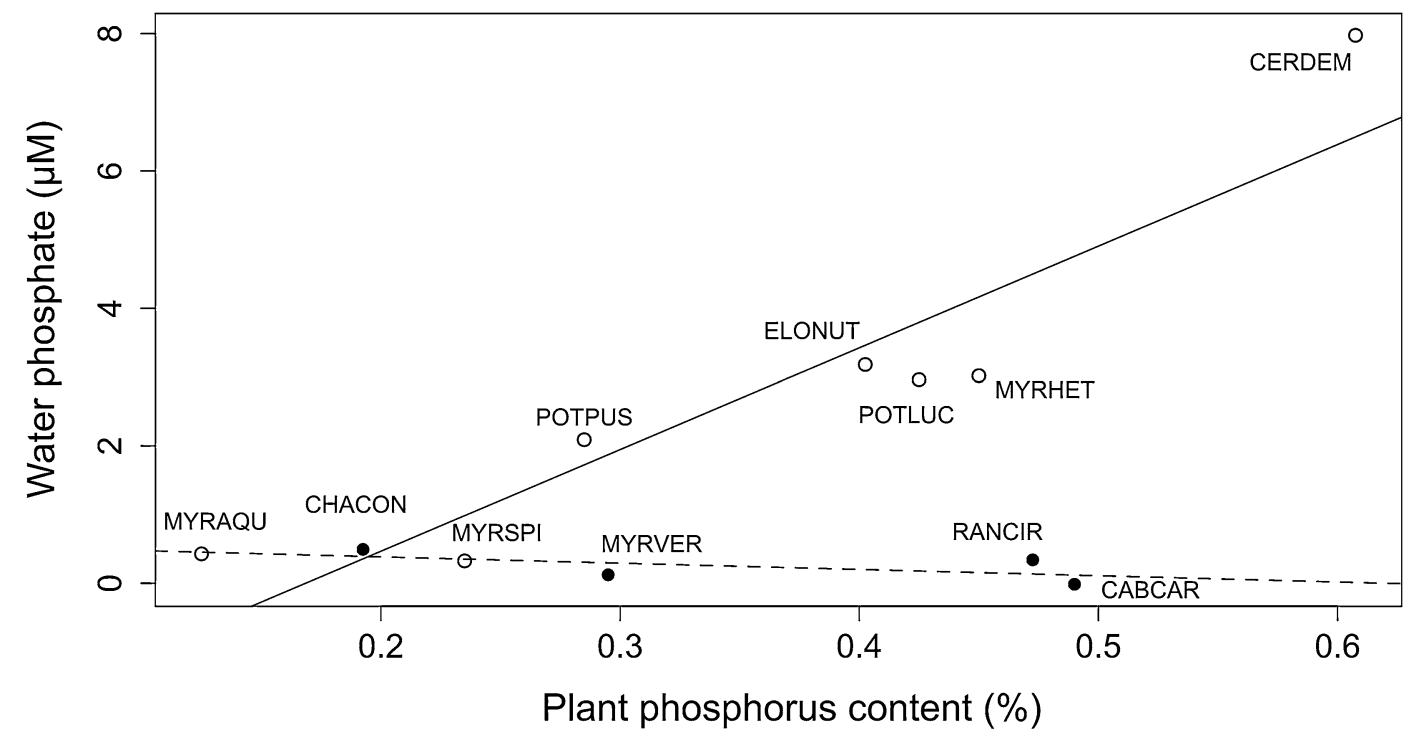

Fig. 4 Among-species relationship of plant phosphorus content (\%) versus the phosphate concentration in the water ( $\mu \mathrm{M})$ for plants that were eaten (open symbols, solid line) and not eaten (closed symbols, dashed line)

Lemoine, 2005; Dorenbosch \& Bakker, 2011; Bakker \& Nolet, 2014); our results confirm the few prior results showing that insect herbivory is not as easily explained (Dorn et al., 2001). We found that $P$. stratiotata larvae did not consume Chara contraria, M. verticillatum, $R$. circinatus and Cabomba caroliniana, despite the favourable nutrient content of several of these plants. In contrast, larvae unexpectedly consumed M. spicatum and M. aquaticum: plants that contained high levels of phenolics, few nutrients, and had unfavourable stoichiometry. Aquatic caterpillars feed differently than most generalist omnivores as they appear to be guided in feeding by secondary metabolites (Erhard \& Gross, 2006), as are many terrestrial insects (Rosenthal \& Berenbaum, 2012). Like some terrestrial Lepidoptera larvae, aquatic caterpillars may ignore quantitative plant defences, which affect nutrient uptake in the gut, as they tolerate them better. For example, Acentria ephemerella, a close relative of $P$. stratiotata, tolerates tannins, which are degraded in its gut in a similar manner as the terrestrial caterpillar Lymantria dispar (Gross et al., 2008). But, they grow faster on a plant low in tannins (Potamogeton perfoliatus) than on a plant high in tannins (M. spicatum) (Choi et al., 2002). These lepidopterans are often sensitive to specific secondary metabolites (Newman, 1991; Gross \& Bakker, 2012). Erhard and Gross (2006) showed that flavonoids of
E. nuttallii reduced the feeding by A. ephemerella, although these flavonoids did not increase larval mortality. Secondary metabolites probably affected insect preference in our trials but these are not linked to any of our measured plant traits. For the plants that insects consumed though, we observed large differences in larval growth, indicating that in contrast to plant preference, insect fitness and density may critically depend on plant quality.

Within $96 \mathrm{~h}$, the pooled caterpillar mass differed greatly among the eleven plant species treatments. It is likely that caterpillars gained mass in some treatments, whereas in others they lost mass, due to variation in their consumption of the eleven plant species offered. Furthermore, P. stratiotata and other aquatic Lepidoptera such as A. ephemerella or Munroessa gyralis typically grow very fast on plants of high quality (e.g. Dorn et al., 2001), which can lead to a fast biomass increase. The observed growth efficiency of 10-20\% dry mass consumed to caterpillar mass matches with literature on lepidopteran and herbivore growth efficiency (Scriber \& Feeny, 1979; Elser et al., 2000).

Final caterpillar dry mass was positively related to the plant nitrogen content of their food, and negatively related to plant $\mathrm{C}: \mathrm{N}$ and $\mathrm{C}: \mathrm{P}$ ratios. Nitrogen likely drives this relationship, as plant species contained similar amounts of carbon, while the relation between phosphorus and dry mass was not significant. 
Moreover, neither total phenolics nor the ratio of phenolics to either nitrogen or phosphorus was related to larval mass, which indicates that phenolics did not limit larval growth, but nutrients did. This matches previous findings that both nitrogen and phosphorus can limit insect growth (Newman, 1991; Perkins et al., 2004). As nitrogen and phosphorus were correlated, though only marginally significant, it was difficult to disentangle their separate effects.

Herbivory can release nitrogen and phosphorus and thereby affect nutrient cycling (Pinowska, 2002; Vanni, 2002). Likewise, we show that consumption by $P$. stratiotata can affect nutrient release and water quality as the larvae released phosphorus to the water. Interestingly, the phosphorus release depended more on the phosphorus content of plants than on the fresh mass consumed, which may be related to differences in ash content of the plants that affected fresh mass. The mechanism behind the release of phosphate is unknown, as it can have leaked from damaged plants, diffused from faecal pellets, or may have been directly excreted by caterpillars. The release of phosphate, along with larval preference, can alter plant species composition as undamaged species, such as $C$. contraria or $C$. caroliniana, could benefit by taking up the recycled phosphate when growing in a multispecies macrophyte community. If no macrophytes are left due to insect herbivory, phytoplankton may take up the nutrients and outcompete macrophytes (Scheffer et al., 2001). In contrast to phosphate, we measured no increase of nitrate, nitrite or ammonium concentrations following insect herbivory. This may have resulted from a more efficient assimilation of nitrogen than of phosphorus by herbivores, from nutrient uptake or from denitrification by bacteria.

Besides nutrient release, herbivory also induced brownification of the water, probably due to an increase in dissolved organic carbon and its subsequent breakdown into humic acids (Graneli, 2012). The intensity of herbivore-induced brownification varied among plant species, and was most intense for P. lucens, E. nuttallii and M. spicatum. Decomposition of organic plant matter depends on various factors that influence microbial growth including phenolic compounds, redox state and nutrient content of organic matter (Freeman et al., 2001). In our data, there was no apparent relation between any of these factors and the extent of brownification that we observed for the tested plant species.
Insect herbivores can strongly damage macrophytes and alter vegetation composition (Newman, 1991; Johnson et al., 1997; Gross et al., 2001), especially if fish predation is limited (Miler, 2008). Dense patches of native and exotic macrophytes provide macroinvertebrates with refuge to predation (Diehl, 1988; Manatunge et al., 2000; Grutters et al., 2015) and may facilitate outbreaks of herbivorous insects. In such outbreaks, $P$. stratiotata might shift aquatic vegetation towards non-edible species like $C$. contraria, $R$. circinatus or C. caroliniana as predicted by our feeding trials. Indirectly, caterpillar feeding can also induce brownification, which inhibits the growth of native plants more than that of exotic plants (Mormul et al.. 2012), and which may allow herbivorous insects to indirectly shift species composition towards exotic species like E. nuttallii that can tolerate low levels of light. Furthermore, herbivore-induced phosphorus release depended on plant species, which could increase phosphorus availability for phytoplankton or nonedible plants, or even stimulate algal blooms.

We conclude that herbivorous insects can directly or indirectly affect aquatic ecosystems, macrophyte abundance and species composition. In addition, our results indicate that $P$. stratiotata can provide biotic resistance to the invasion by multiple exotic plants, and that this herbivore seems to be hindered more by stoichiometric constraints of its food than by plant origin. However, the determinants of plant preference for native or exotic species of this caterpillar remain unknown.

Acknowledgements We thank Nico Helmsing, Erik Reichman and Dennis Waasdorp for helping with chemical plant analyses. We are grateful for feedback from one anonymous reviewer. This work was supported by ALWNWO Biodiversity Works Grant 841.11.011. This is NIOOKNAW publication 5934.

Open Access This article is distributed under the terms of the Creative Commons Attribution 4.0 International License (http:// creativecommons.org/licenses/by/4.0/), which permits unrestricted use, distribution, and reproduction in any medium, provided you give appropriate credit to the original author(s) and the source, provide a link to the Creative Commons license, and indicate if changes were made.

\section{References}

Bakker, E. S. \& B. A. Nolet, 2014. Experimental evidence for enhanced top-down control of freshwater macrophytes with nutrient enrichment. Oecologia 176: 825-836. 
Barko, J. W. \& R. M. Smart, 1986. Sediment-related mechanisms of growth limitation in submersed macrophytes. Ecology 67: 1328-1340.

Barko, J. W., R. M. Smart, D. G. McFarland \& R. L. Chen, 1988. Interrelationships between the growth of Hydrilla verticillata (L.f.) Royle and sediment nutrient availability. Aquatic Botany 32: 205-216.

Bolser, R. C., M. E. Hay, N. Lindquist, W. Fenical \& D. Wilson, 1998. Chemical defenses of freshwater macrophytes against crayfish herbivory. Journal of Chemical Ecology 24: 1639-1658.

Choi, C., C. Bareiss, O. Walenciak \& E. M. Gross, 2002. Impact of polyphenols on growth of the aquatic herbivore Acentria ephemerella. Journal of Chemical Ecology 28: 2245-2256.

Colautti, R. I., A. Ricciardi, I. A. Grigorovich \& H. J. MacIsaac, 2004. Is invasion success explained by the enemy release hypothesis? Ecology Letters 7: 721-733.

Cronin, G., D. M. Lodge, M. E. Hay, M. Miller, A. M. Hill, T. Horvath, R. C. Bolser, N. Lindquist \& M. Wahl, 2002. Crayfish feeding preferences for freshwater macrophytes: the influence of plant structure and chemistry. Journal of Crustacean Biology 22: 708-718.

Diehl, S., 1988. Foraging efficiency of three freshwater fishes: effects of structural complexity and light. Oikos 53: 207-214.

Dorenbosch, M. \& E. S. Bakker, 2011. Herbivory in omnivorous fishes: effect of plant secondary metabolites and prey stoichiometry. Freshwater Biology 56: 1783-1797.

Dorn, N. J., G. Cronin \& D. M. Lodge, 2001. Feeding preferences and performance of an aquatic lepidopteran on macrophytes: plant hosts as food and habitat. Oecologia 128: 406-415.

Dudgeon, D., A. H. Arthington, M. O. Gessner, Z. I. Kawabata, D. J. Knowler, C. Lévêque, R. J. Naiman, A. H. PrieurRichard, D. Soto \& M. L. J. Stiassny, 2006. Freshwater biodiversity: importance, threats, status and conservation challenges. Biological Reviews 81: 163-182.

Elger, A. \& M. H. Barrat-Segretain, 2002. Use of the pond snail Lymnaea stagnalis (L.) in laboratory experiments for evaluating macrophyte palatability. Archiv Fur Hydrobiologie 153: 669-683.

Elger, A. \& D. Lemoine, 2005. Determinants of macrophyte palatability to the pond snail Lymnaea stagnalis. Freshwater Biology 50: 86-95.

Elser, J. J., W. F. Fagan, R. F. Denno, D. R. Dobberfuhl, A. Folarin, A. Huberty, S. Interlandi, S. S. Kilham, E. McCauley, K. L. Schulz, E. H. Siemann \& R. W. Sterner, 2000. Nutritional constraints in terrestrial and freshwater food webs. Nature 408: 578-580.

Erhard, D. \& E. M. Gross, 2006. Allelopathic activity of Elodea canadensis and Elodea nuttallii against epiphytes and phytoplankton. Aquatic Botany 85: 203-211.

Fornoff, F. \& E. M. Gross, 2014. Induced defense mechanisms in an aquatic angiosperm to insect herbivory. Oecologia 175: 173-185.

Freeman, C., N. Ostle \& H. Kang, 2001. An enzymic 'latch' on a global carbon store. Nature 409: 149.

Gaevskaya, N. S., 1969. The role of higher aquatic plants in the nutrition of the animals of freshwater basins. D.G.M. Muller (Trans.), K.H. Mann (Ed.), vol. 3, 629 pp.
Graneli, W., 2012. Brownification of Lakes. In: Encyclopedia of Lakes and RESERVOIRS. Springer, New York: 117-119.

Gross, E. M. \& E. S. Bakker, 2012. The role of plant secondary metabolites in freshwater macrophyte-herbivore interactions: Limited or unexplored chemical defences. The Integrative Role of Plant Secondary Metabolites in Ecological Systems British Ecological Society/Cambridge University Press, Sussex: 154-169.

Gross, E. M., R. L. Johnson \& N. G. Hairston Jr, 2001. Experimental evidence for changes in submersed macrophyte species composition caused by the herbivore Acentria ephemerella (Lepidoptera). Oecologia 127: 105-114.

Gross, E. M., A. Brune \& O. Walenciak, 2008. Gut pH, redox conditions and oxygen levels in an aquatic caterpillar: potential effects on the fate of ingested tannins. Journal of Insect Physiology 54: 462-471.

Grutters, B. M. C., B. J. A. Pollux, W. C. E. P. Verberk \& E. S. Bakker, 2015. Native and non-native plants provide similar refuge to invertebrate prey, but less than artificial plants. PLoS ONE 10(4): e0124455.

Harrison, S. S., M. Dobson, J. Lancaster \& R. Briers, 2008. Evolutionary Drivers and the Ecological Traits of Adults Aquatic Insects. In: Aquatic Insects Challenges to Populations London: Proceedings of the Royal Entomological Society's 24th Symposium: 250-267.

Hussner, A., 2012. Alien aquatic plant species in European countries. Weed Research 52: 297-306.

Johnson, R. L., E. M. Gross \& N. G. Hairston Jr, 1997. Decline of the invasive submersed macrophyte Myriophyllum spicatum (Haloragaceae) associated with herbivory by larvae of Acentria ephemerella (Lepidoptera). Aquatic Ecology 31: 273-282.

Johnson, R. L., P. J. Van Dusen, J. A. Toner \& N. G. Hairston, 2000. Eurasian watermilfoil biomass associated with insect herbivores in New York. Journal of Aquatic Plant Management 38: 82-88.

Kay, S. H. \& S. T. Hoyle, 2001. Mail order, the Internet, and invasive aquatic weeds. Journal of Aquatic Plant Management 39: 88-91.

Keane, R. M. \& M. J. Crawley, 2002. Exotic plant invasions and the enemy release hypothesis. Trends in Ecology \& Evolution 17: 164-170.

Langeland, K. A., 1996. Hydrilla verticillata (LF) Royle (Hydrocharitaceae), "The Perfect Aquatic Weed". Castanea: 293-304.

Lekic, M., 1971. Ecology of the aquatic insect species Parapoynx stratiotata L. (Pyraustidae, Lepidoptera). Journal of Scientific Agricultral Research Yugoslavia 23: 49-63.

MacDougall, A. S. \& R. Turkington, 2005. Are invasive species the drivers or passengers of change in degraded ecosystems? Ecology 86: 42-55.

Manatunge, J., T. Asaeda \& T. Priyadarshana, 2000. The influence of structural complexity on fish-zooplankton interactions: a study using artificial submerged macrophytes. Environmental Biology of Fishes 58: 425-438.

Martin, G. D. \& J. A. Coetzee, 2011. Pet stores, aquarists and the internet trade as modes of introduction and spread of invasive macrophytes in South Africa. Water SA 37: 371-380. 
Mattson Jr, W. J., 1980. Herbivory in relation to plant nitrogen content. Annual Review of Ecology and Systematics 11: $119-161$.

Meyerson, L. A. \& H. A. Mooney, 2007. Invasive alien species in an era of globalization. Frontiers in Ecology and the Environment 5: 199-208.

Miler, O., 2008. The aquatic moth Acentria ephemerella as a key species in submerged aquatic vegetation: direct and traitmediated interactions with predators and food plants. $\mathrm{PhD}$ thesis, University of Konstanz, Konstanz.

Mole, S. \& P. G. Waterman, 1987. A critical analysis of techniques for measuring tannins in ecological studies. Oecologia 72: 137-147.

Mormul, R. P., J. Ahlgren, M. K. Ekvall, L. A. Hansson \& C. Brönmark, 2012. Water brownification may increase the invasibility of a submerged non-native macrophyte. Biological Invasions 14: 2091-2099.

Morrison, W. E. \& M. E. Hay, 2011. Herbivore preference for native vs. exotic plants: generalist herbivores from multiple continents prefer exotic plants that are evolutionarily naive. PLoS ONE 6: e17227.

Newman, R. M., 1991. Herbivory and detritivory on freshwater macrophytes by invertebrates: a review. Journal of the North American Benthological Society 10: 89-114.

Oreska, M. P. \& D. C. Aldridge, 2011. Estimating the financial costs of freshwater invasive species in Great Britain: a standardized approach to invasive species costing. Biological Invasions 13: 305-319.

Parker, J. D. \& M. E. Hay, 2005. Biotic resistance to plant invasions? Native herbivores prefer non-native plants. Ecology Letters 8: 959-967.

Penuelas, J., J. Sardans, J. Llusia, S. M. Owen, J. Carnicer, T. W. Giambelluca, E. L. Rezende, M. Waite \& U. Niinemets, 2010. Faster returns on 'leaf economics' and different biogeochemical niche in invasive compared with native plant species. Global Change Biology 16: 2171-2185.

Perkins, M. C., H. A. Woods, J. F. Harrison \& J. J. Elser, 2004. Dietary phosphorus affects the growth of larval Manduca sexta. Archives of Insect Biochemistry and Physiology 55: 153-168.

Pinowska, A., 2002. Effects of snail grazing and nutrient release on growth of the macrophytes Ceratophyllum demersum and Elodea canadensis and the filamentous green alga Cladophora sp. Hydrobiologia 479: 83-94.

Rosenthal, G. A. \& M. R. Berenbaum, 2012. Herbivores: Their Interactions with Secondary Plant Metabolites: Ecological and Evolutionary Processes, Vol. 2., 2012 Academic Press, New York.
Roulet, N. \& T. R. Moore, 2006. Environmental chemistry: browning the waters. Nature 444: 283-284.

Scheffer, M., S. Carpenter, J. A. Foley, C. Folke \& B. Walker, 2001. Catastrophic shifts in ecosystems. Nature 413: 591-596.

Scriber, J. M. \& P. Feeny, 1979. Growth of herbivorous caterpillars in relation to feeding specialization and to the growth form of their food plants. Ecology 60: 829-850.

Simberloff, D., L. Souza, M. A. Nuñez, M. N. Barrios-Garcia \& W. Bunn, 2011. The natives are restless, but not often and mostly when disturbed. Ecology 93: 598-607.

Smith, V. H., G. D. Tilman \& J. C. Nekola, 1999. Eutrophication: impacts of excess nutrient inputs on freshwater, marine, and terrestrial ecosystems. Environmental Pollution 100: 179-196.

Smolders, A. J. P., L. H. T. Vergeer, G. van der Velde \& J. G. M. Roelofs, 2000. Phenolic contents of submerged, emergent and floating leaves of aquatic and semi-aquatic macrophyte species: why do they differ? Oikos 91: 307-310.

Smolders, A. J. P., H. B. M. Tomassen, M. V. Mullekom, L. P. M. Lamers \& J. G. M. Roelofs, 2003. Mechanisms involved in the re-establishment of Sphagnum-dominated vegetation in rewetted bog remnants. Wetlands Ecology and Management 11: 403-418.

Solarz, S. L. \& R. M. Newman, 2001. Variation in hostplant preference and performance by the milfoil weevil, Euhrychiopsis lecontei Dietz, exposed to native and exotic watermilfoils. Oecologia 126: 66-75.

Spencer, N. R. \& M. Lekic, 1974. Prospects for biological control of Eurasian watermilfoil. Weed Science 22: 401-404.

Sterner, R. W. \& J. J. Elser, 2002. Ecological Stoichiometry: The Biology of Elements from Molecules to the Biosphere. Princeton University Press, Princeton.

Vallenduuk, H. J. \& H. M. J. Cuppen, 2004. The aquatic living caterpillars (Lepidoptera: Pyraloidea: Crambidae) of Central Europe. A key to the larvae and autecology. Lauterbornia 49: 1-17.

Vanni, M. J., 2002. Nutrient cycling by animals in freshwater ecosystems. Annual Review of Ecology and Systematics 33: 341-370.

Xiong, W., D. Yu, Q. Wang, C. H. Liu \& L. G. Wang, 2008. A snail prefers native over exotic freshwater plants: implications for the enemy release hypotheses. Freshwater Biology 53: 2256-2263.

Zehnsdorf, A., A. Hussner, F. Eismann, H. Rönicke \& A. Melzer, 2015. Management options of invasive Elodea nuttallii and Elodea canadensis. Limnologica-Ecology and Management of Inland Waters 51: 110-117. 